\title{
Exposure to COVID-19-Related Information and its Association With Mental Health Problems in Thailand: Nationwide, Cross-sectional Survey Study
}

Pajaree Mongkhon ${ }^{1,2}$, PhD; Chidchanok Ruengorn ${ }^{2,3}, \mathrm{PhD}$; Ratanaporn Awiphan ${ }^{2,3}, \mathrm{PhD}$; Kednapa Thavorn ${ }^{2,45,6}$, $\mathrm{PhD}$; Brian Hutton ${ }^{4,5,6}, \mathrm{PhD}$; Nahathai Wongpakaran ${ }^{7}, \mathrm{MD}$; Tinakon Wongpakaran ${ }^{7}, \mathrm{MD}$; Surapon Nochaiwong ${ }^{2,3}$, PharmD

\footnotetext{
${ }^{1}$ Division of Pharmacy Practice, Department of Pharmaceutical Care; Unit of Excellence on Research in Health Outcomes and Patient Safety in Elderly, School of Pharmaceutical Sciences, University of Phayao, Phayao, Thailand

${ }^{2}$ Pharmacoepidemiology and Statistics Research Center, Faculty of Pharmacy, Chiang Mai University, Chiang Mai, Thailand

${ }^{3}$ Department of Pharmaceutical Care, Faculty of Pharmacy, Chiang Mai University, Chiang Mai, Thailand

${ }^{4}$ School of Epidemiology and Public Health, Faculty of Medicine, University of Ottawa, Ottawa, ON, Canada

${ }^{5}$ Institute of Clinical and Evaluative Sciences, ICES uOttawa, Ottawa, ON, Canada

${ }^{6}$ Ottawa Hospital Research Institute, Ottawa Hospital, Ottawa, ON, Canada

${ }^{7}$ Department of Psychiatry, Faculty of Medicine, Chiang Mai University, Chiang Mai, Thailand
}

\section{Corresponding Author:}

Surapon Nochaiwong, PharmD

Department of Pharmaceutical Care

Faculty of Pharmacy

Chiang Mai University

239, Suthep Road

Chiang Mai, 50200

Thailand

Phone: 66899973365

Email: surapon.nochaiwong@gmail.com

\author{
Abstract \\ Background: The COVID-19 pandemic has had a negative impact on both the physical and mental health of individuals \\ worldwide. Evidence regarding the association between mental health problems and information exposure among Thai citizens \\ during the COVID-19 outbreak is limited.
}

Objective: This study aimed to explore the relationship between information exposure and mental health problems during the COVID-19 pandemic in Thailand.

Methods: Between April 21 and May 4, 2020, we conducted a cross-sectional, nationwide online survey of the general population in Thailand. We categorized the duration of exposure to COVID-19-related information as follows: $<1 \mathrm{~h} /$ day (reference group), 1-2 h/day, and $\geq 3 \mathrm{~h} /$ day. Mental health outcomes were assessed using the Patient Health Questionnaire-9, the Generalized Anxiety Disorder-7 scale, the Perceived Stress Scale-10, and the Insomnia Severity Index for symptoms of depression, anxiety, perceived stress, and insomnia, respectively. Multivariable logistic regression models were used to evaluate the relationship between information exposure and the risk of developing the aforementioned symptoms. An ancillary analysis using multivariable multinomial logistic regression models was also conducted to assess the possible dose-response relationship across the severity strata of mental health problems.

Results: Of the 4322 eligible participants, 4004 (92.6\%) completed the online survey. Of them, 1481 (37.0\%), 1644 (41.1\%), and 879 (22.0\%) participants were exposed to COVID-19-related information for less than 1 hour per day, 1 to 2 hours per day, or 3 or more hours per day, respectively. The major source of information related to the COVID-19 pandemic was social media (95.3\%), followed by traditional media (68.7\%) and family members (34.9\%). Those exposed to information for 3 or more hours per day had a higher risk of developing symptoms of depression (adjusted odds ratio [OR] 1.35, 95\% CI 1.03-1.76; $P=.03$ ), anxiety (adjusted OR 1.88, 95\% CI 1.43-2.46; $P<.001$ ), and insomnia (adjusted OR 1.52, 95\% CI 1.17-1.97; $P=.001$ ) than people exposed to information for less than 1 hour per day. Meanwhile, people exposed to information for 1 to 2 hours per day were 
only at risk of developing symptoms of anxiety (adjusted OR 1.35, 95\% CI 1.08-1.69; $P=.008$ ). However, no association was found between information exposure and the risk of perceived stress. In the ancillary analysis, a dose-response relationship was observed between information exposure of 3 or more hours per day and the severity of mental health problems.

Conclusions: These findings suggest that social media is the main source of COVID-19-related information. Moreover, people who are exposed to information for 3 or more hours per day are more likely to develop psychological problems, including depression, anxiety, and insomnia. Longitudinal studies investigating the long-term effects of COVID-19-related information exposure on mental health are warranted.

(J Med Internet Res 2021;23(2):e25363) doi: 10.2196/25363

\section{KEYWORDS}

coronavirus; COVID-19; insomnia; mental health; social media; depression; anxiety; stress; psychosocial problem

\section{Introduction}

On December 31, 2019, the world witnessed the occurrence of a new public health emergency, the COVID-19 outbreak, in Wuhan, China [1]. On March 11, 2020, the World Health Organization (WHO) declared COVID-19 a pandemic due to the rapid global spread of the causative virus [2]. As of January 6, 2021, approximately 86 million confirmed cases and over 1.8 million deaths due to COVID-19 were reported worldwide. In addition to the physical effects of COVID-19, the COVID-19 pandemic has negatively affected the mental health of the public globally [3-5].

During the outbreak, people may need some information from the media to better understand the situation and determine strategies to protect their health. Information-seeking behavior may reduce anxiety caused by uncertainty during a disease outbreak or disaster [6]. In contrast, excessive consumption of information provided by the media may create new problems. Large volumes of information may amplify the perception of risk, and consumption of fear-related information may have a negative impact on consumers who cannot discern real news from fake news or cannot obtain a more balanced view of the media coverage of said event [7]. This infodemic has the potential to affect the population's mental health and well-being. Many previous studies have illustrated that media exposure is associated with adverse psychological outcomes in different contexts, including bioterrorism [8], war [9], natural disasters [10], and mental health of the general population [11].

Since the start of the COVID-19 pandemic, people have been highly dependent on information from the media, especially those who are not directly affected by the disease. People who are quarantined or isolated may also experience psychological problems due to the widespread media coverage related to the COVID-19 outbreak as well as financial difficulties. In addition, patients with confirmed or suspected COVID-19 may experience disease progression and transmit the virus to their families and friends. Numerous studies have investigated the association between COVID-19-related information exposure and mental health [12-17]. A previous study conducted in Wuhan demonstrated that social media exposure was positively associated with anxiety and depression during the COVID-19 outbreak, after controlling for covariates [4]. These results were supported by those of studies conducted in Germany [18], Saudi Arabia [19], and China [20] indicating that the frequency and duration of media or information exposure may predispose individuals to mental distress. These findings highlight the need to address mental health problems as part of public health policy.

In Thailand, the government announced a lockdown on March 26, 2020, in an effort to stop the spread of COVID-19. This measure seemed to have greatly prevented or slowed down the nationwide spread of the disease. However, during this lockdown, people who were quarantined or isolated might have developed psychological distress and other mental health problems due to media information overload and fear of the effects of COVID-19. To our knowledge, no study has reported the relationship between information exposure and mental health in the general population in Thailand during the COVID-19 outbreak. Therefore, we conducted a cross-sectional nationwide online survey to investigate the relationship between information exposure and symptoms of depression, anxiety, stress, and insomnia during the COVID-19 pandemic in Thailand.

\section{Methods}

\section{Study Design and Study Population}

The Health Outcomes and Mental Health Care Evaluation Survey: Under the Pandemic Situation of COVID-19 (HOME-COVID-19) was a cross-sectional online survey administered via the SurveyMonkey platform. The HOME-COVID-19 study was specifically developed by our research group and comprised baseline sociodemographic characteristics and a set of measurement tools for evaluating mental health and psychosocial problems; we used the Thai versions of the validated measurement tools or tools developed by our team. The questionnaire was initially revised by a panel of health care professionals, including three epidemiologists, two psychiatrists, one social scientist, and two hospital directors. This was further validated by a pilot survey of 30 health care professionals and 30 individuals from the general population. Further details about the HOME-COVID-19 study have been provided in a previous study [21]. This was a nationwide survey conducted between April 21 and May 4, 2020. This survey was performed by first selecting a sample of individuals from the general population in Thailand. Convenience sampling and a snowball strategy were used for participant recruitment through various social media networks (ie, public websites, Facebook, LINE, Twitter, and Instagram). The characteristics of the target population and the questionnaire used were subsequently presented [21]. We included Thai citizens, permanent residents, and nonresidents with employment or work permits who could 
read and communicate in the Thai language and were at least 18 years of age during the survey period. We excluded individuals who lacked internet access, were unable to complete the online survey, and spent less than 2 minutes, or more than 60 minutes, completing the survey, which likely made their data invalid. Based on the HOME-COVID-19 survey protocol [21], the participants spent approximately 20 to 30 minutes completing the survey.

Written consent was obtained from the participants in the first section of the online survey before completing the questionnaire. This study was approved by the Research Ethics Committees of the Faculties of Public Health (ET010/2020) and Pharmacy (23/2563), Chiang Mai University, Thailand. The study was reported in accordance with the Strengthening the Reporting of Observational Studies in Epidemiology statement [22] and the Checklist for Reporting Results of Internet E-Surveys guidelines [23].

\section{Measurements}

\section{COVID-19-Related Information Exposure}

Information on the duration of information exposure was obtained by asking the participants how often they were exposed to news and information about the COVID-19 pandemic. The duration of information exposure was categorized as follows: $<1 \mathrm{~h} /$ day, 1-2 h/day, or $\geq 3 \mathrm{~h} /$ day. Sources of information were classified as traditional media (eg, newspaper, television, radio, etc), social media (eg, Facebook, Twitter, blogs, etc), colleagues and neighbors, family members, government organizations (eg, Ministry of Health), and others.

\section{Mental Health Outcomes}

The mental health outcomes of interest included symptoms of depression, anxiety, perceived stress, and insomnia during the COVID-19 pandemic. The aforementioned symptoms were assessed using the Thai versions of the validated measurement tools. The measurement tools used in this study were as follows:

1. The Patient Health Questionnaire-9 (PHQ-9) consists of nine items that reflect the severity of depression symptoms. The score ranges from 0 to 27, and an overall PHQ-9 score of 9 or higher indicates depression (see Multimedia Appendix 1) [24].

2. The Generalized Anxiety Disorder-7 (GAD-7) scale comprises seven items that reflect the severity of anxiety symptoms. The total score ranges from 0 to 21 , and a GAD-7 score of 5 or higher indicates anxiety (see Multimedia Appendix 2) [25].

3. The Perceived Stress Scale-10 (PSS-10) is a 5-point Likert scale consisting of 10 items. The scores range from 0 to 40 , and a score of 14 or higher indicates perceived stress (see Multimedia Appendix 3) [26].

4. The Insomnia Severity Index (ISI) is an 8-item scale used to assess the nature, severity, and impact of insomnia. The scores range from 0 to 28 points and vary based on the severity of insomnia. In our study, an ISI score of 7 or higher indicated insomnia symptoms (see Multimedia Appendix 4) [27].

\section{Power}

Using the HOME-COVID-19 survey protocol, the target sample size for this study was estimated based on the findings of previous studies conducted during the COVID-19 outbreak, which reported a prevalence rate of mental health and psychosocial problems of $3.3 \%$ to $75.5 \%$ [21]. To compensate for a design effect of 2.0 and an estimated response rate of $60 \%$, a minimum sample size of 2492 participants was obtained to achieve a power of $80 \%$ and a type I error $\alpha$ level of .05 . However, there was no restriction on the maximum number of participants in the online survey.

\section{Statistical Analysis}

Descriptive analyses were performed to describe the characteristics of participants among the three information exposure groups. Categorical variables were expressed as the number (\%), while continuous variables were expressed as the mean (SD) or median (IQR), as appropriate. Intergroup differences in the duration of COVID-19-related information exposure were tested using the $\chi^{2}$ or Fisher exact tests; analysis of covariance and the Kruskal-Wallis test were used to evaluate categorical and continuous variables, respectively.

For the primary analysis, multivariable logistic regression models were used to explain the association between the duration of daily information exposure and the risk of depression (PHQ-9 score 9), anxiety (GAD-7 score 5), perceived stress (PSS-10 score 14), and insomnia (ISI score 8) during the COVID-19 outbreak, after controlling for the covariates of each outcome. The covariates included age, sex, marital status, education level, religion, occupation, region of residence, living status, reimbursement scheme, mental illness history, chronic noncommunicable disease history, income loss, financial problems, confirmed cases in the community, working from home, quarantine status, fear of COVID-19, and resilient coping. The degree of fear against COVID-19 was measured using a 10 -point rating scale. The scores were then grouped as follows: no or minimal fear (0-3 points), moderate fear (4-6 points), and severe fear (7-10 points). Resilient coping was defined using the Brief Resilient Coping Scale: low-resilient copers (4-13 points), moderate-resilient copers (14-16 points), and high-resilient copers (17-20 points) [28].

An auxiliary analysis was conducted using multivariable multinomial logistic regression models to explain the association between the duration of information exposure and the severity of mental health problems. Sensitivity analysis was performed using a multivariable linear regression model to confirm the linear relationship between the duration of COVID-19-related information exposure and the risk of mental health problems. Meanwhile, a multivariable ordinal logistic regression model was used to examine the association between the duration of information exposure and severity strata of each mental health problem while controlling for the aforementioned covariates.

The effect estimates were presented as odds ratios (ORs), along with their corresponding $95 \% \mathrm{CIs}$, and weighted to match the estimates for the national population and internet users in all models based on data from the National Statistical Office under the Ministry of Information and Communication Technology. 
All data were analyzed using Stata, version 14.0 (StataCorp LP). A 2-tailed test with $P<.05$ was considered statistically significant.

\section{Results}

\section{Baseline Characteristics}

A total of 4997 participants were invited to complete an online survey, but only 4381 participants responded to the survey. Among 4381 participants, 59 individuals who were under 18 years or age at the time of the survey and/or spent less than 2 minutes, or more than 60 minutes, completing the survey were excluded. Of the 4322 participants who met the eligibility criteria, 4004 completed the online survey (see Figure 1). Of the 4004 participants who completed the survey, 2619 (65.4\%) were female, 1231 (30.7\%) were male, and $154(3.8 \%)$ selected other for the sex question. The mean age was 29.1 (SD 10.8) years; moreover, $3208(80.1 \%)$ participants were single. As shown in Table 1, 127 (3.2\%) participants had completed junior high school, while 1893 (47.3\%) had completed high vocational education. Among the 4004 participants who completed the survey, 1589 (39.7\%) were college students, $526(13.1 \%)$ were government or state enterprise employees, and $500(12.5 \%)$ were private enterprise employees. The participants were mainly from the noncapital city and its environs $(2579 / 4004,64.4 \%)$ in Thailand, whereas 1425 (35.6\%) were from the capital city and its environs. Only $383(9.6 \%)$ participants had no fear of COVID-19, whereas 1940 (48.4\%) had a severe fear of COVID-19. The majority of the participants were low-resilient copers $(1756 / 4004,43.9 \%)$, while 678 (16.9\%) were highly resilient.

Figure 1. Flow diagram for study participants. HOME-COVID-19: Health Outcomes and Mental Health Care Evaluation Survey: Under the Pandemic Situation of COVID-19.

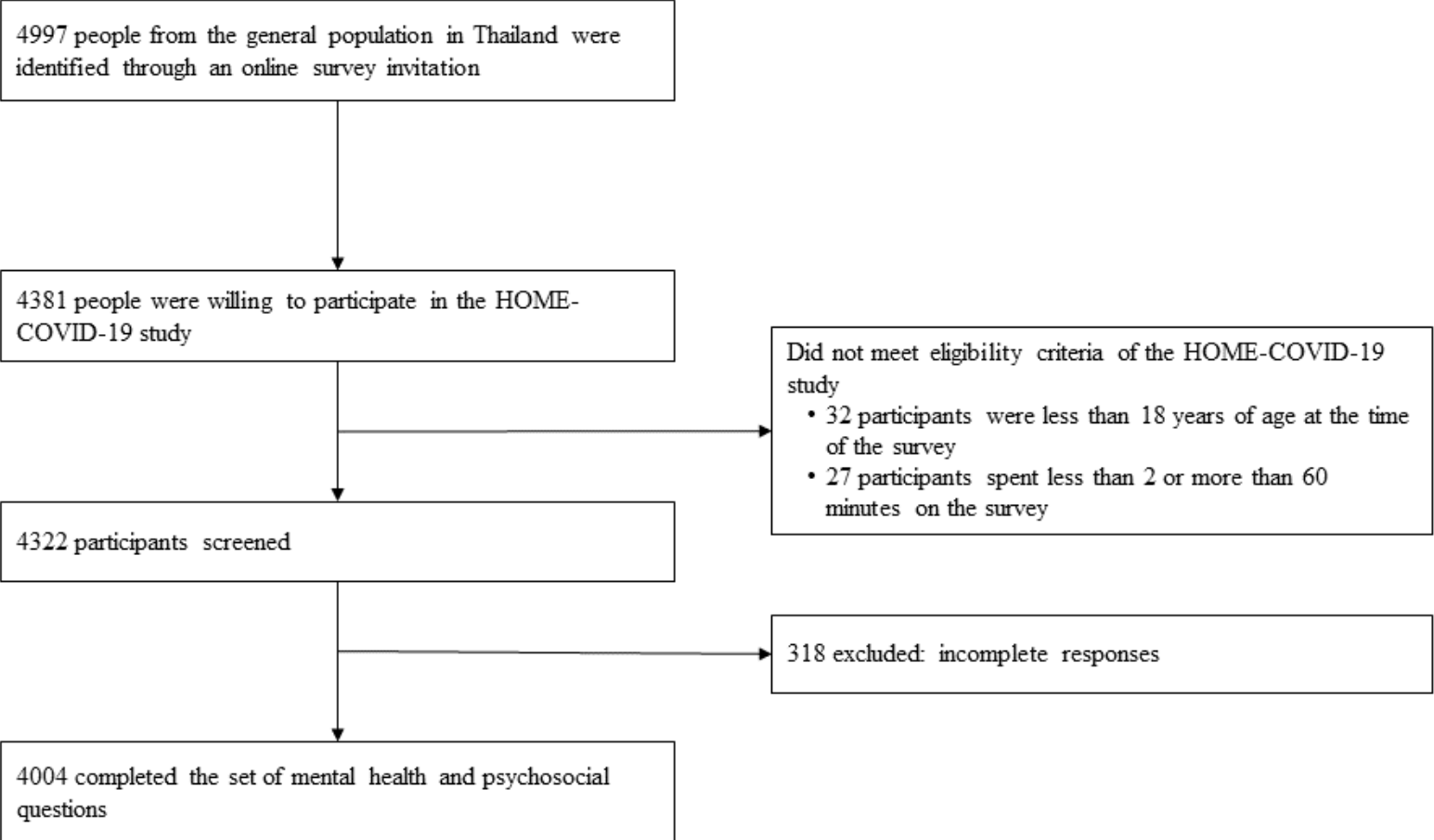


Table 1. Participant characteristics and the duration of exposure to COVID-19-related information in Thailand, from April 21 to May 4, 2020.

\begin{tabular}{|c|c|c|c|c|c|}
\hline \multirow[t]{2}{*}{ Participant characteristics } & \multirow[t]{2}{*}{ Overall $(\mathrm{N}=4004), \mathrm{n}(\%)$} & \multicolumn{4}{|c|}{ Duration of exposure to COVID-19-related information } \\
\hline & & $<1 \mathrm{~h} /$ day $(\mathrm{n}=1481)$ & $1-2 \mathrm{~h} /$ day $(\mathrm{n}=1644)$ & $\geq 3$ h/day $(n=879)$ & $P$ value \\
\hline \multicolumn{6}{|l|}{ Sociodemographic data, n (\%) } \\
\hline \multicolumn{6}{|l|}{ Age } \\
\hline Total sample (years), mean (SD) & $29.1(10.8)$ & $27.8(9.8)$ & $28.9(10.8)$ & $31.5(12.1)$ & $<.001$ \\
\hline$\leq 30$ years & $2659(66.4)$ & $1028(69.4)$ & $1112(67.6)$ & $519(59.0)$ & $<.001$ \\
\hline $31-50$ years & $1088(27.2)$ & $392(26.5)$ & $427(26.0)$ & $269(30.6)$ & \\
\hline$\geq 51$ years & $257(6.4)$ & $61(4.1)$ & $105(6.4)$ & $91(10.4)$ & \\
\hline \multicolumn{6}{|l|}{ Sex } \\
\hline Male & $1231(30.7)$ & $485(32.8)$ & $500(30.4)$ & $246(28.0)$ & .12 \\
\hline Female & $2619(65.4)$ & $936(63.2)$ & $1087(66.1)$ & $596(67.8)$ & \\
\hline Other & $154(3.9)$ & $60(4.0)$ & $57(3.5)$ & $37(4.2)$ & \\
\hline \multicolumn{6}{|l|}{ Marital status } \\
\hline Single & $3208(80.1)$ & $1228(82.9)$ & $1335(81.2)$ & $645(73.4)$ & $<.001$ \\
\hline Married or domestic partnership & $693(17.3)$ & $219(14.8)$ & $277(16.8)$ & $197(22.4)$ & \\
\hline Divorced, widowed, or separated & $103(2.6)$ & $34(2.3)$ & $32(2.0)$ & $37(4.2)$ & \\
\hline \multicolumn{6}{|l|}{ Education level } \\
\hline $\begin{array}{l}\text { Illiterate, primary school, or junior high } \\
\text { school }\end{array}$ & $127(3.2)$ & $54(3.6)$ & $46(2.8)$ & $27(3.1)$ & $<.001$ \\
\hline $\begin{array}{l}\text { Senior high school, diploma, or high } \\
\text { vocational school }\end{array}$ & $1893(47.3)$ & $799(54.0)$ & $749(45.6)$ & $345(39.2)$ & \\
\hline Bachelor's degree & $1559(38.9)$ & $511(34.5)$ & $648(39.4)$ & $400(45.5)$ & \\
\hline Higher education & $425(10.6)$ & $117(7.9)$ & $201(12.2)$ & $107(12.2)$ & \\
\hline \multicolumn{6}{|l|}{ Religion } \\
\hline Irreligious & $375(9.4)$ & $138(9.3)$ & $171(10.4)$ & $66(7.5)$ & .23 \\
\hline Buddhist & $3454(86.3)$ & $1271(85.8)$ & $1402(85.3)$ & 781 (88.9) & \\
\hline Christian & $100(2.5)$ & $43(2.9)$ & $42(2.5)$ & $15(1.7)$ & \\
\hline Muslim & $70(1.7)$ & $26(1.8)$ & $28(1.7)$ & $16(1.8)$ & \\
\hline Other & $5(0.1)$ & $3(0.2)$ & $1(0.1)$ & $1(0.1)$ & \\
\hline \multicolumn{6}{|l|}{ Occupation } \\
\hline Unemployed or retired & $391(9.8)$ & $130(8.8)$ & $148(9.0)$ & $113(12.9)$ & $<.001$ \\
\hline Farmer or laborer & $451(11.3)$ & $195(13.2)$ & $156(9.5)$ & $100(11.4)$ & \\
\hline Self-employed & $415(10.4)$ & $146(9.9)$ & $154(9.4)$ & $115(13.1)$ & \\
\hline Government or state enterprise employee & $526(13.1)$ & $139(9.4)$ & $260(15.8)$ & $127(14.4)$ & \\
\hline College student & $1589(39.7)$ & $667(45.0)$ & $659(40.1)$ & $263(29.9)$ & \\
\hline Private enterprise employee & $500(12.5)$ & $165(11.1)$ & $211(12.8)$ & $124(14.1)$ & \\
\hline Freelance or other & $132(3.3)$ & $39(2.6)$ & $56(3.4)$ & $37(4.2)$ & \\
\hline \multicolumn{6}{|l|}{ Region of residence } \\
\hline Capital city and its environs & $1425(35.6)$ & $496(33.5)$ & $623(37.9)$ & $306(34.8)$ & .03 \\
\hline Noncapital city and its environs & $2579(64.4)$ & $985(66.5)$ & $1021(62.1)$ & $573(65.2)$ & \\
\hline \multicolumn{6}{|l|}{ Living status } \\
\hline Alone & $576(14.4)$ & $195(13.2)$ & $239(14.5)$ & $142(16.2)$ & .25 \\
\hline With family & $3164(79.0)$ & $1179(79.6)$ & $1299(79.0)$ & $686(78.0)$ & \\
\hline
\end{tabular}




\begin{tabular}{|c|c|c|c|c|c|}
\hline \multirow[t]{2}{*}{ Participant characteristics } & \multirow[t]{2}{*}{ Overall $(\mathrm{N}=4004), \mathrm{n}(\%)$} & \multicolumn{4}{|c|}{ Duration of exposure to COVID-19-related information } \\
\hline & & $<1 \mathrm{~h} /$ day $(\mathrm{n}=1481)$ & $1-2$ h/day $(n=1644)$ & $\geq 3 \mathrm{~h} /$ day $(\mathrm{n}=879)$ & $P$ value \\
\hline With others & $264(6.6)$ & $107(7.2)$ & $106(6.5)$ & $51(5.8)$ & \\
\hline \multicolumn{6}{|l|}{ Reimbursement scheme } \\
\hline Government or state enterprises & $539(13.5)$ & $172(11.6)$ & $254(15.5)$ & $113(12.9)$ & .008 \\
\hline Universal coverage scheme & $1329(33.2)$ & $524(35.4)$ & $515(31.3)$ & $290(33.0)$ & \\
\hline Social security scheme & $1161(29.0)$ & $423(28.6)$ & $460(28.0)$ & $278(31.6)$ & \\
\hline Self-payment or other & $975(24.3)$ & $362(24.4)$ & $415(25.2)$ & $198(22.5)$ & \\
\hline \multicolumn{6}{|l|}{ History of mental illness } \\
\hline Yes & $359(9.0)$ & $125(8.4)$ & $142(8.6)$ & $92(10.5)$ & .21 \\
\hline No & $3645(91.0)$ & 1356 (91.6) & $1502(91.4)$ & $787(89.5)$ & \\
\hline \multicolumn{6}{|c|}{ History of chronic noncommunicable disease $\mathrm{a}^{\mathrm{a}}$} \\
\hline Yes & $599(15.0)$ & $182(12.3)$ & $218(13.3)$ & $199(22.6)$ & $<.001$ \\
\hline No & $3405(85.0)$ & $1299(87.7)$ & $1426(86.7)$ & $680(77.4)$ & \\
\hline \multicolumn{6}{|c|}{ Economic burden and issues with regard to the COVID-19 outbreak, $n(\%)$} \\
\hline \multicolumn{6}{|c|}{ Income loss during the COVID-19 outbreak } \\
\hline Yes & $1664(41.6)$ & $524(35.4)$ & $660(40.2)$ & $480(54.6)$ & $<.001$ \\
\hline No & $2340(58.4)$ & $957(64.6)$ & $984(59.8)$ & $399(45.4)$ & \\
\hline \multicolumn{6}{|c|}{ Financial problems during the COVID-19 outbreak } \\
\hline Yes & $2012(50.2)$ & $668(45.1)$ & $800(48.7)$ & $544(61.9)$ & $<.001$ \\
\hline No & $1992(49.8)$ & $813(54.9)$ & $844(51.3)$ & $335(38.1)$ & \\
\hline \multicolumn{6}{|l|}{ Confirmed cases in the community } \\
\hline No & $2562(64.0)$ & $888(60.0)$ & $1067(64.9)$ & $607(69.1)$ & $<.001$ \\
\hline Yes & $641(16.0)$ & $246(16.6)$ & $260(15.8)$ & $135(15.4)$ & \\
\hline Not known & $801(20.0)$ & $347(23.4)$ & $317(19.3)$ & $137(15.6)$ & \\
\hline \multicolumn{6}{|l|}{ Working from home } \\
\hline Yes & $3139(78.4)$ & $1142(77.1)$ & $1298(79.0)$ & $699(79.5)$ & .30 \\
\hline No & $865(21.6)$ & 339 (22.9) & $346(21.0)$ & $180(20.5)$ & \\
\hline \multicolumn{6}{|l|}{ Quarantine status } \\
\hline Never & $1781(44.5)$ & $610(41.2)$ & $751(45.7)$ & $420(47.8)$ & .004 \\
\hline Past & 1575 (39.3) & $631(42.6)$ & $636(38.7)$ & $308(35.0)$ & \\
\hline Current & $648(16.2)$ & $240(16.2)$ & $257(15.6)$ & $151(17.2)$ & \\
\hline \multicolumn{6}{|l|}{ Fear of COVID-19 } \\
\hline None or minimal & $383(9.6)$ & $163(11.0)$ & $140(8.5)$ & $80(9.1)$ & .04 \\
\hline Moderate & $1681(42.0)$ & $593(40.0)$ & $729(44.3)$ & $359(40.8)$ & \\
\hline Severe & $1940(48.4)$ & $725(49.0)$ & $775(47.1)$ & $440(50.1)$ & \\
\hline \multicolumn{6}{|l|}{ Resilient coping } \\
\hline Low-resilient coper & $1756(43.9)$ & $683(46.1)$ & $701(42.6)$ & $372(42.3)$ & .12 \\
\hline Medium-resilient coper & $1570(39.2)$ & $559(37.7)$ & $670(40.8)$ & $341(38.8)$ & \\
\hline High-resilient coper & $678(16.9)$ & $239(16.1)$ & $273(16.6)$ & $166(18.9)$ & \\
\hline
\end{tabular}

${ }^{\mathrm{a}}$ Includes diabetes mellitus, hypertension, dyslipidemia, stroke and heart disease, chronic kidney disease, chronic lung disease, and cancer. 


\section{Information Exposure}

Of the 4004 participants, 1644 (41.1\%) were exposed to information 1 to 2 hours per day, followed by less than 1 hour per day $(1481 / 4004,37.0 \%)$ and 3 or more hours per day
$(879 / 4004,22.0 \%)$. The sources of COVID-19-related information were social media $(95.3 \%, 95 \%$ CI 94.6-95.9), followed by traditional media $(68.7 \%, 95 \% \mathrm{CI} 67.2-70.1)$, and family members (34.9\%, 95\% CI 33.4-36.4) (see Figure 2).

Figure 2. Sources of COVID-19-related information in Thailand. One person can be exposed to more than one source.

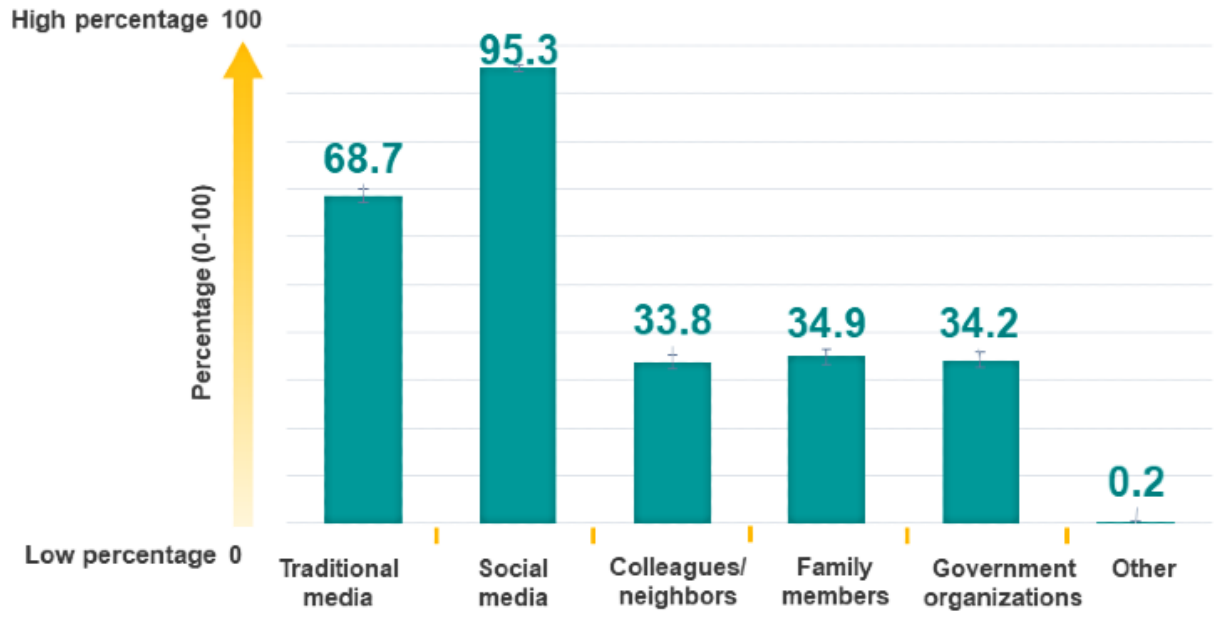

\section{Mental Health and Information Exposure}

Table 2 presents the results of the multivariable logistic regression analysis that was performed to explain the association between the duration of information exposure and the risk of mental health problems during the COVID-19 pandemic, after controlling for covariates. In the primary analysis, participants who were exposed to COVID-19-related information for 3 or more hours per day had higher odds of developing symptoms of depression than those exposed to COVID-19-related information for less than 1 hour per day (adjusted OR 1.35, 95\% CI 1.03-1.76; $P=.03$ ). Similarly, participants who were exposed to COVID-19-related information for 3 or more hours per day were more likely to develop anxiety and insomnia than those exposed to COVID-19-related information for less than 1 hour per day (adjusted OR 1.88, 95\% CI 1.43-2.46; $P<.001$; and adjusted OR $1.52,95 \%$ CI 1.17-1.97; $P=.001$, respectively). Meanwhile, participants who were exposed to COVID-19-related information for 1 to 2 hours per day only had a risk of developing anxiety symptoms (adjusted OR 1.35, $95 \%$ CI 1.08-1.69; $P=.008)$. No association was observed between the duration of information exposure and the risk of perceived stress in the general population during the study period in Thailand. 
Table 2. Mental health outcomes according to the duration of exposure to COVID-19-related information: multivariable logistic regression model.

\begin{tabular}{|c|c|c|c|}
\hline $\begin{array}{l}\text { Symptoms developed and duration of exposure to COVID-19-related in- } \\
\text { formation }\end{array}$ & Number of cases, n (\%) & Adjusted $\mathrm{OR}^{\mathrm{a}}(95 \% \mathrm{CI})^{\mathrm{b}}$ & $P$ value \\
\hline \multicolumn{4}{|l|}{ Depression: Patient Health Questionnaire-9 } \\
\hline$<1$ h/day $(\mathrm{n}=1481)$ & $567(38.3)$ & Reference (1.00) & $\mathrm{N} / \mathrm{A}^{\mathrm{c}}$ \\
\hline $1-2$ h/day $(n=1644)$ & $696(42.3)$ & $1.08(0.86-1.35)$ & .52 \\
\hline$\geq 3$ h/day $(n=879)$ & $391(44.5)$ & $1.35(1.03-1.76)$ & .03 \\
\hline \multicolumn{4}{|l|}{ Anxiety: Generalized Anxiety Disorder-7 } \\
\hline$<1$ h/day $(\mathrm{n}=1481)$ & $578(39.0)$ & Reference (1.00) & N/A \\
\hline $1-2$ h/day $(n=1644)$ & $701(42.6)$ & $1.35(1.08-1.69)$ & .008 \\
\hline$\geq 3$ h/day $(n=879)$ & $446(50.7)$ & $1.88(1.43-2.46)$ & $<.001$ \\
\hline \multicolumn{4}{|l|}{ Stress: Perceived Stress Scale-10 } \\
\hline$<1 \mathrm{~h} /$ day $(\mathrm{n}=1481)$ & $1076(72.7)$ & Reference (1.00) & N/A \\
\hline $1-2$ h/day $(n=1644)$ & $1200(73.0)$ & $0.96(0.74-1.23)$ & .72 \\
\hline$\geq 3$ h/day $(n=879)$ & $640(72.8)$ & $1.01(0.75-1.36)$ & .93 \\
\hline \multicolumn{4}{|l|}{ Insomnia: Insomnia Severity Index } \\
\hline$<1$ h/day $(\mathrm{n}=1481)$ & $760(51.3)$ & Reference (1.00) & \\
\hline $1-2$ h/day $(n=1644)$ & $877(53.3)$ & $1.04(0.84-1.29)$ & .71 \\
\hline$\geq 3 \mathrm{~h} /$ day $(\mathrm{n}=879)$ & $520(59.2)$ & $1.52(1.17-1.97)$ & .001 \\
\hline
\end{tabular}

${ }^{\mathrm{a} O R}$ : odds ratio.

${ }^{\mathrm{b}}$ ORs and corresponding 95\% CIs are presented as weighted according to the national population and internet users in Thailand. ORs were adjusted for age, sex, marital status, education level, religion, occupation, region of residence, living status, reimbursement scheme, history of mental illness, history of chronic noncommunicable disease, income loss, financial problems, confirmed cases in the community, working from home, quarantine status, fear of COVID-19, and resilient coping.

${ }^{\mathrm{c}} \mathrm{N} / \mathrm{A}$ : not applicable.

In an ancillary analysis, using a multivariable multinomial logistic regression model ( $<1 \mathrm{~h} /$ day of information exposure [reference group]), a dose-response relationship was noted between exposure to COVID-19-related information for 3 or more hours per day and the severity of mental health problems, particularly anxiety symptoms (see Table 3). For instance,

individuals exposed to COVID-19-related information for 3 or more hours per day demonstrated substantial effect modification in terms of the severity strata of anxiety symptoms: the adjusted ORs were 1.35 (95\% CI 0.99-1.83; $P=.06$ ), 2.87 (95\% CI $1.91-4.33 ; P<.001)$, and 4.45 (95\% CI $2.45-8.08 ; P<.001)$ for mild, moderate, and severe anxiety symptoms, respectively. 
Table 3. Multivariable multinomial logistic regression model results of the duration of exposure to COVID-19-related information and severity of mental health problems.

\begin{tabular}{|c|c|c|c|c|c|}
\hline \multirow[t]{3}{*}{ Severity of mental health problems } & \multirow{3}{*}{$\begin{array}{l}\text { Number of cases } \\
(\mathrm{N}=4004), \mathrm{n}(\%)\end{array}$} & \multicolumn{4}{|c|}{ Duration of exposure to COVID-19-related information } \\
\hline & & \multicolumn{2}{|l|}{$1-2 \mathrm{~h} /$ day } & \multicolumn{2}{|l|}{$\geq 3 \mathrm{~h} /$ day } \\
\hline & & $\begin{array}{l}\text { Estimated adjusted } \mathrm{OR}^{\mathrm{a}} \\
(95 \% \mathrm{CI})^{\mathrm{b}}\end{array}$ & $P$ value & $\begin{array}{l}\text { Estimated adjusted OR } \\
(95 \% \mathrm{CI})^{\mathrm{b}}\end{array}$ & $P$ value \\
\hline \multicolumn{6}{|c|}{ Depression: Patient Health Questionnaire-9 } \\
\hline None or minimal ( $<9$ points) & $2350(58.7)$ & Reference (1.00) & $\mathrm{N} / \mathrm{A}^{\mathrm{c}}$ & Reference (1.00) & N/A \\
\hline Mild (9-14 points) & $1024(25.6)$ & $1.05(0.82-1.34)$ & .70 & $1.18(0.86-1.60)$ & .31 \\
\hline Moderate (15-19 points) & $389(9.7)$ & $1.10(0.76-1.60)$ & .60 & $1.49(0.97-2.28)$ & .07 \\
\hline Severe ( $\geq 20$ points) & $241(6.0)$ & $1.13(0.70-1.84)$ & .61 & $2.23(1.27-3.92)$ & .005 \\
\hline \multicolumn{6}{|c|}{ Anxiety: Generalized Anxiety Disorder-7 } \\
\hline None or minimal ( $<5$ points $)$ & $2279(56.9)$ & Reference (1.00) & N/A & Reference (1.00) & N/A \\
\hline Mild (5-9 points) & $1117(27.9)$ & $1.31(1.03-1.66)$ & .03 & $1.35(0.99-1.83)$ & .06 \\
\hline Moderate (10-14 points) & $411(10.3)$ & $1.33(0.91-1.93)$ & .14 & $2.87(1.91-4.33)$ & $<.001$ \\
\hline Severe ( $\geq 15$ points) & $197(4.9)$ & $1.79(1.06-3.02)$ & .03 & $4.45(2.45-8.08)$ & $<.001$ \\
\hline \multicolumn{6}{|l|}{ Stress: Perceived Stress Scale-10 } \\
\hline None or low (<14 points) & $1088(27.2)$ & Reference (1.00) & N/A & Reference (1.00) & N/A \\
\hline Moderate (14-26 points) & $2550(63.7)$ & $0.93(0.72-1.20)$ & .59 & $0.96(0.71-1.30)$ & .80 \\
\hline High ( $\geq 27$ points) & $366(9.1)$ & $1.22(0.80-1.88)$ & .36 & $1.76(1.09-2.85)$ & .02 \\
\hline \multicolumn{6}{|l|}{ Insomnia: Insomnia Severity Index } \\
\hline None or minimal (<8 points) & $1847(46.1)$ & Reference (1.00) & N/A & Reference (1.00) & N/A \\
\hline Mild (8-14 points) & $1576(39.4)$ & $0.99(0.79-1.24)$ & .94 & $1.41(1.07-1.86)$ & .02 \\
\hline Moderate (15-21 points) & $486(12.1)$ & $1.29(0.91-1.83)$ & .15 & $2.03(1.34-3.07)$ & .001 \\
\hline Severe ( $\geq 22$ points) & $95(2.4)$ & $0.89(0.45-1.76)$ & .74 & $1.48(0.69-3.18)$ & .31 \\
\hline
\end{tabular}

${ }^{\mathrm{a} O R}$ : odds ratio.

${ }^{\mathrm{b}}$ Multinomial logistic regression was performed using information exposure of $<1 \mathrm{~h} /$ day as the reference group. ORs and corresponding $95 \%$ CIs are presented as weighted according to the national population and internet users in Thailand. ORs were adjusted for age, sex, marital status, education level, religion, occupation, region of residence, living status, reimbursement scheme, history of mental illness, history of chronic noncommunicable disease, income loss, financial problems, confirmed cases in the community, working from home, quarantine status, fear of COVID-19, and resilient coping.

${ }^{\mathrm{c}} \mathrm{N} / \mathrm{A}$ : not applicable.

\section{Sensitivity Analysis}

Sensitivity analysis was performed by considering the mental health outcomes. A linear relationship was seen between adverse mental health outcomes and the duration of COVID-19-related information exposure, particularly for 3 or more hours per day (see Multimedia Appendix 5, Table S1). Moreover, after using a multivariable ordinal logistic regression model, our findings remained the same compared to those in the primary analysis (see Multimedia Appendix 5, Table S2).

\section{Data Sharing}

Data will be shared upon reasonable request and with permission according to the Health Outcomes and Mental Health Care Evaluation Survey Research Group data release policy.

\section{Discussion}

\section{Principal Findings}

This nationwide online survey was conducted in Thailand. The results indicated that many Thai people used social media as the main source of information during the COVID-19 pandemic. Most participants were exposed to COVID-19-related information for 1 to 2 hours per day. Participants who were exposed to information for 3 or more hours per day had a higher risk of developing depression, anxiety, and insomnia.

Our results were in line with those of a previous study conducted in Wuhan, China, demonstrating that social media exposure was associated with higher odds of developing anxiety and depression [17]. Moreover, previous studies [17,18,20,29] showed that not only the frequency but also the daily duration of exposure to COVID-19-related information was associated 
with psychosocial problems [29], which corroborated with our study results. The results of a survey conducted in Germany indicated a positive correlation between COVID-19-related media exposure and the severity of nonspecific anxiety and depression [18]. Similar results were reported in a previous study conducted among the Saudi Arabian general population [19].

In essence, during a lockdown or social isolation, people are exposed to a lot of pandemic-related information, especially through social media, which predisposes them to mental health problems. During a severe social disruption, the mass media are expected to satisfy the needs of individuals for information about operationalized guidance to the public, the response of organizations, and an exchange of views with others [30-32]. However, the amount of information that circulated during the COVID-19 pandemic exceeded the information demand. A recent study indicated that repeated media exposure could lead to anxiety due to the effect of vicarious traumatization [31]. Furthermore, media exposure can cause an infodemic, which is defined as fake news, misinformation, and conspiracy theories, making it difficult for individuals to find trusted information [33]. This infodemic may negatively impact an individual's mental health.

In Thailand, the government issued a national emergency decree, which was put into effect beginning on March 26, 2020, and announced a nationwide curfew on April 3, 2020. People were requested to stay indoors and limit all social contacts. The government also requested that people should wear face masks, practice social distancing, and remain indoors from $10 \mathrm{PM}$ to 4 AM [34]. Due to the implementation of curfews and isolation measures, the number of persons with suspected or confirmed COVID-19 decreased from mid-January to April 6, 2020, which indicated a positive impact of the lockdown on viral transmission reduction and epidemic control [35]. However, the quarantine and isolation measures, coupled with media coverage exposure, increased anxiety and fear in the people, thereby affecting their mental health. Moreover, during the national lockdown and home confinement, the community movement in Thailand had eventually decreased, which resulted in home-based exposure of people to huge amounts of COVID-19-related media information.

Therefore, during a public health crisis, several actions should be taken regarding crisis-related information. First, the media should convey information to the public without sensationalizing the situation and without providing disturbing images to help prevent mental distress. Second, the public should rely on trustworthy sources of information, such as the Centers for Disease Control and Prevention or the WHO, for accurate information. Third, health care providers should play an important role in informing people about practicing protective behaviors [36]. Fourth, public awareness campaigns should be conducted, focusing on the maintenance of mental health in the prevailing situation [37]. Finally, people should spend time with family members who engage in different healthy exercises and sports activities, follow a schedule and routine in daily life, and reduce their time spent on traditional and social media to remain healthy [37]. In terms of mental health policies during the
COVID-19 pandemic, the United Nations suggested the application of a whole-of-society approach to promote, protect, and care for an individual's mental health [38]. Furthermore, public policy solutions would ensure the widespread availability of emergency mental health and psychosocial support. All affected communities require quality mental health services to help their society recover from the effects of the COVID-19 pandemic.

\section{Strengths and Limitations}

This study had several strengths. To our knowledge, this is the first nationwide survey on mental health based on information exposure during the COVID-19 outbreak in Thailand. From a methodological point of view, the analyses were also performed using rigorous statistical approaches to confirm the main findings.

However, our study has some limitations. First, this was a cross-sectional study; therefore, a causal relationship could not be accurately drawn. Second, the survey was conducted online, which is appropriate for short-term evaluation; therefore, the results reflect short-term relationships. Hence, additional longitudinal studies investigating the long-term relationship between mental health and COVID-19-related information exposure are warranted. Third, the survey was conducted over the internet, which is subject to bias due to nonresponse effects and selection bias. Moreover, as information exposure was self-reported, recall bias may be present, and the measures may be influenced by social desirability. Fourth, not everyone in Thailand can access the internet and there could be significant demographic differences between those who can access the internet and those who have limited access to the internet. Thus, selection bias or limited representativeness of the Thai population may be present. Fifth, the majority of the participants were young adults. Only a few older adults participated in the survey; thus, some respondent bias could not be excluded. In addition, the majority of participants $(66.4 \%)$ were below 30 years of age, which might not reflect the Thai society in its entirety. However, internet usage data in Thailand have demonstrated that workers spend the highest average number of hours surfing the internet per day and account for the highest proportion of internet users [39]. The internet usage data of this group of people may potentially represent the internet consumption of the Thai population. Finally, we lacked information on risk perception and self-care behaviors. This information could help encourage self-improvement and self-management during the COVID-19 pandemic, which may improve an individual's overall mental health and wellness.

\section{Conclusions}

Our findings from the nationwide online survey indicated a positive association between information exposure during the COVID-19 pandemic and the occurrence of symptoms of depression, anxiety, and insomnia. The strength of the association increased with the duration of media exposure. However, prospective longitudinal studies are needed to investigate the long-term relationship between information exposure and mental health during and after the COVID-19 pandemic. 


\section{Acknowledgments}

This work was partially supported by the Chiang Mai University, Thailand, with support provided to SN. Its contents are solely the responsibility of the authors and do not necessarily represent the official views of Chiang Mai University. No funding source had any role in the study concept and design; data collection, analysis, and interpretation; writing of the report; or in the decision to submit for publication. We would like to thank all staff and research personnel from the Pharmacoepidemiology and Statistics Research Center, Chiang Mai University, Thailand. Particular thanks are given to the study participants.

\section{Authors' Contributions}

PM and SN had full access to all of the data in the study and take responsibility for the integrity of the data and the accuracy of the data analysis. PM and SN were responsible for the study concept and design. PM, CR, and SN were responsible for the acquisition, analysis, or interpretation of data. PM and SN were responsible for drafting of the manuscript. Critical revision of the manuscript for important intellectual content was performed by KT, BH, NW, and TW. Statistical analysis was performed by PM, CR, and SN. Administrative, technical, or material support was provided by RA. Study supervision was provided by SN.

\section{Conflicts of Interest}

None declared.

\section{Multimedia Appendix 1}

Patient Health Questionnaire-9 (PHQ-9).

[DOCX File, 17 KB-Multimedia Appendix 1]

\section{Multimedia Appendix 2}

Generalized Anxiety Disorder-7 (GAD-7) scale.

[DOCX File, 17 KB-Multimedia Appendix 2]

\section{Multimedia Appendix 3}

Perceived Stress Scale-10 (PSS-10).

[DOCX File, 18 KB-Multimedia Appendix 3]

\section{Multimedia Appendix 4}

Insomnia Severity Index (ISI).

[DOCX File , 18 KB-Multimedia Appendix 4]

\section{Multimedia Appendix 5}

Sensitivity analysis.

[DOCX File , 20 KB-Multimedia Appendix 5]

\section{References}

1. Novel Coronavirus (2019-nCoV): Situation Report - 1. Geneva, Switzerland: World Health Organization; 2020 Jan 21.

URL: https://www.who.int/docs/default-source/coronaviruse/situation-reports/20200121-sitrep-1-2019-ncov.pdf [accessed 2020-09-27]

2. Coronavirus Disease 2019 (COVID-19): Situation Report - 51. Geneva, Switzerland: World Health Organization; 2020 Mar 11. URL: https://www.who.int/docs/default-source/coronaviruse/situation-reports/20200311-sitrep-51-covid-19.pdf [accessed 2020-09-27]

3. Bao Y, Sun Y, Meng S, Shi J, Lu L. 2019-nCoV epidemic: Address mental health care to empower society. Lancet 2020 Feb 22;395(10224):e37-e38 [FREE Full text] [doi: 10.1016/S0140-6736(20)30309-3] [Medline: 32043982]

4. Kang L, Li Y, Hu S, Chen M, Yang C, Yang BX, et al. The mental health of medical workers in Wuhan, China dealing with the 2019 novel coronavirus. Lancet Psychiatry 2020 Mar;7(3):e14. [doi: 10.1016/s2215-0366(20)30047-x]

5. Shigemura J, Ursano RJ, Morganstein JC, Kurosawa M, Benedek DM. Public responses to the novel 2019 coronavirus (2019-nCoV) in Japan: Mental health consequences and target populations. Psychiatry Clin Neurosci 2020 Apr;74(4):281-282 [FREE Full text] [doi: 10.1111/pcn.12988] [Medline: 32034840]

6. Heath RL, Gay CD. Risk communication. Manag Commun Q 2016 Aug 17;10(3):342-372. [doi: 10.1177/0893318997010003004]

7. Kasperson RE, Renn O, Slovic P, Brown HS, Emel J, Goble R, et al. The social amplification of risk: A conceptual framework. Risk Anal 1988 Jun;8(2):177-187 [FREE Full text] [doi: 10.1111/j.1539-6924.1988.tb01168.x] 
8. Dougall AL, Hayward MC, Baum A. Media exposure to bioterrorism: Stress and the anthrax attacks. Psychiatry 2005;68(1):28-42. [doi: 10.1521/psyc.68.1.28.64188] [Medline: 15899708 ]

9. Bodas M, Siman-Tov M, Peleg K, Solomon Z. Anxiety-inducing media: The effect of constant news broadcasting on the well-being of Israeli television viewers. Psychiatry 2015;78(3):265-276. [doi: 10.1080/00332747.2015.1069658] [Medline: 26391834]

10. Hall BJ, Xiong YX, Yip PSY, Lao CK, Shi W, Sou EKL, et al. The association between disaster exposure and media use on post-traumatic stress disorder following Typhoon Hato in Macao, China. Eur J Psychotraumatol 2019;10(1):1558709 [FREE Full text] [doi: 10.1080/20008198.2018.1558709] [Medline: 30693078]

11. Kross E, Verduyn P, Demiralp E, Park J, Lee DS, Lin N, et al. Facebook use predicts declines in subjective well-being in young adults. PLoS One 2013;8(8):e69841 [FREE Full text] [doi: 10.1371/journal.pone.0069841] [Medline: 23967061]

12. Liu JCJ, Tong EMW. The relation between official WhatsApp-distributed COVID-19 news exposure and psychological symptoms: Cross-sectional survey study. J Med Internet Res 2020 Sep 25;22(9):e22142 [FREE Full text] [doi: 10.2196/22142] [Medline: 32877349]

13. Riehm KE, Holingue C, Kalb LG, Bennett D, Kapteyn A, Jiang Q, et al. Associations between media exposure and mental distress among US adults at the beginning of the COVID-19 pandemic. Am J Prev Med 2020 Nov;59(5):630-638 [FREE Full text] [doi: 10.1016/j.amepre.2020.06.008] [Medline: 33011008 ]

14. Bazán P, Azevedo NR, Dias J, Salvatierra V, Sanches L, Lacerda S. COVID-19 information exposure in digital media and implications for employees in the health care sector: Findings from an online survey. Einstein (Sao Paulo) 2020 Nov 26;18:eAO6127. [doi: 10.31744/einstein_journal/2020ao6127]

15. Lee JJ, Kang K, Wang MP, Zhao SZ, Wong JYH, O'Connor S, et al. Associations between COVID-19 misinformation exposure and belief with COVID-19 knowledge and preventive behaviors: Cross-sectional online study. J Med Internet Res 2020 Nov 13;22(11):e22205 [FREE Full text] [doi: 10.2196/22205] [Medline: 33048825]

16. Ruiz-Frutos C, Ortega-Moreno M, Dias A, Bernardes JM, García-Iglesias JJ, Gómez-Salgado J. Information on COVID-19 and psychological distress in a sample of non-health workers during the pandemic period. Int J Environ Res Public Health 2020 Sep 24;17(19):6982 [FREE Full text] [doi: 10.3390/ijerph17196982] [Medline: 32987712]

17. Gao J, Zheng P, Jia Y, Chen H, Mao Y, Chen S, et al. Mental health problems and social media exposure during COVID-19 outbreak. PLoS One 2020;15(4):e0231924 [FREE Full text] [doi: 10.1371/journal.pone.0231924] [Medline: 32298385]

18. Bendau A, Petzold MB, Pyrkosch L, Mascarell Maricic L, Betzler F, Rogoll J, et al. Associations between COVID-19 related media consumption and symptoms of anxiety, depression and COVID-19 related fear in the general population in Germany. Eur Arch Psychiatry Clin Neurosci 2020 Jul 20:1-9 [FREE Full text] [doi: 10.1007/s00406-020-01171-6] [Medline: 32691135]

19. Zakout Y, Alreshidi F, Elsaid R, Ahmed H. The magnitude of COVID-19 related stress, anxiety and depression associated with intense mass media coverage in Saudi Arabia. AIMS Public Health 2020;7(3):664-678 [FREE Full text] [doi: 10.3934/publichealth.2020052] [Medline: 32968685]

20. Yao H. The more exposure to media information about COVID-19, the more distressed you will feel. Brain Behav Immun $2020 \mathrm{Jul} ; 87: 167-169$ [FREE Full text] [doi: 10.1016/j.bbi.2020.05.031] [Medline: 32413557]

21. Nochaiwong S, Ruengorn C, Awiphan R, Ruanta Y, Boonchieng W, Nanta S. Mental health circumstances among health care workers and general public under the pandemic situation of COVID-19 (HOME-COVID-19). Medicine 2020 Jun 26;99(26):e20751. [doi: 10.1097/md.0000000000020751]

22. von Elm E, Altman DG, Egger M, Pocock SJ, Gøtzsche PC, Vandenbroucke JP, STROBE Initiative. Strengthening the Reporting of Observational Studies in Epidemiology (STROBE) statement: Guidelines for reporting observational studies. BMJ 2007 Oct 20;335(7624):806-808 [FREE Full text] [doi: 10.1136/bmj.39335.541782.AD] [Medline: 17947786]

23. Eysenbach G. Improving the quality of web surveys: The Checklist for Reporting Results of Internet E-Surveys (CHERRIES). J Med Internet Res 2004 Sep 29;6(3):e34 [FREE Full text] [doi: 10.2196/jmir.6.3.e34] [Medline: 15471760]

24. Lotrakul M, Sumrithe S, Saipanish R. Reliability and validity of the Thai version of the PHQ-9. BMC Psychiatry 2008 Jun 20;8(1):1. [doi: 10.1186/1471-244x-8-46]

25. Spitzer RL, Kroenke K, Williams JBW, Löwe B. A brief measure for assessing generalized anxiety disorder: The GAD-7. Arch Intern Med 2006 May 22;166(10):1092-1097. [doi: 10.1001/archinte.166.10.1092] [Medline: 16717171]

26. Wongpakaran N, Wongpakaran T. The Thai version of the PSS-10: An investigation of its psychometric properties. Biopsychosoc Med 2010 Jun 12;4:6 [FREE Full text] [doi: 10.1186/1751-0759-4-6] [Medline: 20540784]

27. Morin CM, Belleville G, Bélanger L, Ivers H. The Insomnia Severity Index: Psychometric indicators to detect insomnia cases and evaluate treatment response. Sleep 2011 May 01;34(5):601-608 [FREE Full text] [doi: 10.1093/sleep/34.5.601] [Medline: 21532953]

28. Sinclair VG, Wallston KA. The development and psychometric evaluation of the Brief Resilient Coping Scale. Assessment 2004 Mar;11(1):94-101. [doi: 10.1177/1073191103258144] [Medline: 14994958]

29. Huang Y, Zhao N. Generalized anxiety disorder, depressive symptoms and sleep quality during COVID-19 outbreak in China: A web-based cross-sectional survey. Psychiatry Res 2020 Jun;288:112954 [FREE Full text] [doi:

10.1016/j.psychres.2020.112954] [Medline: 32325383] 
30. Ball-Rokeach S, DeFleur M. A dependency model of mass-media effects. Communic Res 2016 Jun 30;3(1):3-21. [doi: $10.1177 / 009365027600300101]$

31. Liu C, Liu Y. Media exposure and anxiety during COVID-19: The mediation effect of media vicarious traumatization. Int J Environ Res Public Health 2020 Jun 30;17(13):4720 [FREE Full text] [doi: 10.3390/ijerph17134720] [Medline: 32630054]

32. Lowrey W. Media dependency during a large-scale social disruption: The case of September 11. Mass Commun Soc 2004 Jul;7(3):339-357. [doi: 10.1207/s15327825mcs0703 5]

33. The Lancet Infectious Diseases. The COVID-19 infodemic. Lancet Infect Dis 2020 Aug;20(8):875 [FREE Full text] [doi: 10.1016/S1473-3099(20)30565-X] [Medline: $\underline{\text { 32687807] }}$

34. Coronavirus Disease 2019 (COVID-19): WHO Thailand Situation Report. Geneva, Switzerland: World Health Organization; 2020 Mar 25. URL: https://www.who.int/docs/default-source/searo/thailand/2020-03-25-tha-sitrep-32-covid19-final. pdf?sfvrsn=adce58ef 0 [accessed 2020-09-27]

35. Dechsupa S, Assawakosri S, Phakham S, Honsawek S. Positive impact of lockdown on COVID-19 outbreak in Thailand. Travel Med Infect Dis 2020;36:101802 [FREE Full text] [doi: 10.1016/j.tmaid.2020.101802] [Medline: 32569811]

36. Garfin DR, Silver RC, Holman EA. The novel coronavirus (COVID-2019) outbreak: Amplification of public health consequences by media exposure. Health Psychol 2020 May;39(5):355-357 [FREE Full text] [doi: 10.1037/hea0000875] [Medline: 32202824]

37. Javed B, Sarwer A, Soto EB, Mashwani Z. The coronavirus (COVID-19) pandemic's impact on mental health. Int J Health Plann Manage 2020 Sep;35(5):993-996 [FREE Full text] [doi: 10.1002/hpm.3008] [Medline: 32567725]

38. Policy Brief: COVID-19 and the Need for Action on Mental Health. New York, NY: United Nations; 2020 May 13. URL: https://unsdg.un.org/sites/default/files/2020-05/UN-Policy-Brief-COVID-19-and-mental-health.pdf [accessed 2020-10-24]

39. Office of Policy and Strategic Affairs, Electronic Transactions Development Agency (ETDA), Ministry of Digital Economy and Society. Thailand Internet User Behavior 2019. Bangkok, Thailand: Electronic Transactions Development Agency (ETDA); 2020. URL: https://www.slideshare.net/ETDAofficialRegist/thailand-internet-user-behavior-2019 [accessed 2021-02-03]

\section{Abbreviations}

GAD-7: Generalized Anxiety Disorder-7

HOME-COVID-19: Health Outcomes and Mental Health Care Evaluation Survey: Under the Pandemic Situation of COVID-19

ISI: Insomnia Severity Index

OR: odds ratio

PHQ-9: Patient Health Questionnaire-9

PSS-10: Perceived Stress Scale-10

WHO: World Health Organization

Edited by G Eysenbach; submitted 29.10.20; peer-reviewed by J Hoogervorst, A Bregenzer; comments to author 23.12.20; revised
version received 12.01.21; accepted 29.01.21; published 12.02.21
Please cite as:
Mongkhon P, Ruengorn C, Awiphan R, Thavorn K, Hutton B, Wongpakaran N, Wongpakaran T, Nochaiwong S
Exposure to COVID-19-Related Information and its Association With Mental Health Problems in Thailand: Nationwide, Cross-sectional
Survey Study
J Med Internet Res 2021;23(2):e25363
URL: $\underline{\text { http://www.jmir.org/2021/2/e25363/ }}$
doi: $10.2196 / 25363$
PMID: $\underline{33523828}$

CPajaree Mongkhon, Chidchanok Ruengorn, Ratanaporn Awiphan, Kednapa Thavorn, Brian Hutton, Nahathai Wongpakaran, Tinakon Wongpakaran, Surapon Nochaiwong. Originally published in the Journal of Medical Internet Research (http://www.jmir.org), 12.02.2021. This is an open-access article distributed under the terms of the Creative Commons Attribution License (https://creativecommons.org/licenses/by/4.0/), which permits unrestricted use, distribution, and reproduction in any medium, provided the original work, first published in the Journal of Medical Internet Research, is properly cited. The complete bibliographic information, a link to the original publication on http://www.jmir.org/, as well as this copyright and license information must be included. 